\title{
Prevalence and Determinants of Depression, Anxiety and Stress Among Psychiatric Nurses in Ghana: a Cross Sectional Study
}

Sampson Opoku Agyemang ( $\sim$ sampson.opoku@ucc.edu.gh )

University of Cape Coast

Jerry Paul Ninnoni

University of Cape Coast

Nancy Innocentia Ebu Enyan

University of Cape Coast

\section{Research Article}

Keywords: Anxiety, Depression, Mental health, Nursing, Risk factors, Stress

Posted Date: November 8th, 2021

DOI: https://doi.org/10.21203/rs.3.rs-1040468/v1

License: (c) (i) This work is licensed under a Creative Commons Attribution 4.0 International License.

Read Full License 


\section{Abstract}

Background: The job demands and stress associated with the nursing profession put nurses on an escalating risk to exhibit psychiatric morbidity such as anxiety and depression. This study assessed the prevalence and risk factors of depression, anxiety and stress among nurses working in public psychiatric hospitals in Ghana.

Methods: A cross-sectional design was used for this study. Proportionate and simple random sampling method were used to select 311 respondents for the study. Data was collected using a questionnaire which comprised Beck's Depression Inventory, Beck's Anxiety Inventory and Perceived Stress Scale. Data was analysed using descriptive statistics and a multinomial logistic regression.

Results: The results showed that $92 \%$ and $96.5 \%$ of mental health nurses experienced minimal depression and low anxiety respectively. In addition, $56.6 \%$ and $42.8 \%$ experienced low and moderate stress respectively. There was a positive association between educational level and depression whereas, a negative association existed between educational level and anxiety and stress. Also, mental health nurses who work at the OPD and Administration were more likely to experience anxiety and stress.

Conclusion: The findings of this study suggest that, higher level of educational opportunities for mental health nurses leads to decreases anxiety among nurses. Also, the work environment needs to be made conducive to promote the psychological wellbeing of nurses. Additionally, interventions on the management of depression, anxiety and stress by nurses in mental health hospitals need to be instituted, thereby, improving the health of nurses working in mental health hospitals.

\section{Background}

Nursing profession is demanding and expose nurses to work related stress, anxiety and depression [1]. Depression, anxiety and stress are among the commonly reported mental disorders and significantly contribute to the global burden of disease [2]. It is estimated that globally, $4.4 \%$ of the world's population suffer from depression and $3.6 \%$ from anxiety disorders [3].

Depression is a severe mental health disorder which symptoms include loss of interest in pleasurable activities, feelings of sadness, guilt, low self-esteem, sleep disturbance and difficulties in concentration [4]. Out of about 450 million people who suffer from mental health disorders globally, approximately 150 million of them suffer from depression [5]. Depression is linked to dissatisfaction with life among nurses working in various health care settings [6].

The way an individual's body respond to perceived threat is known as anxiety [7]. Symptoms of anxiety include increased blood pressure, respiration rate, pulse rate, tension, sweating and chest pain. Stress is a reaction that is started when an person perceives that external or internal demands exceed resources mobilized by the individual [8]. It is the feelings of an individual when he anticipates that his demands are 
more than the resources available to him to fulfil those demands [9]. When an individual is not able to manage the negative impact of stress, they exhibit symptoms of anxiety and depression [10].

The high prevalence of anxiety, depression, stress and burnout at the workplace among nurses reflects the nature of the nursing profession [11-14]. The job demands and stress associated with the nursing profession put nurses on an escalating risk to exhibit psychiatric morbidity such as anxiety and depression that can affect all aspects of their personal, family and professional life $[12,14,15]$.

In order to deliver quality and competent health care to patients who are admitted to hospitals, the mental health care needs of nurses is important and need to be supported to maintain optimal mental health care in order to render quality health care to clients [16]. Although mental health nurses are considered to be at higher risk of developing depression, anxiety and stress as compared to other categories of nurses [17], few studies investigated the mental health of psychiatric nurses especially in Ghana where resources are constraint. The aim of this study was to assess the prevalence and determinants of depression, anxiety and stress among psychiatric nurses in the psychiatric hospitals in Ghana. Specifically, this study sought to: determine the prevalence of depression, anxiety and stress among nurses; determine the prevalence of work place risk factors of depression, anxiety and stress among nurses; and identify sociodemographic characteristics that predict depression, anxiety and stress among nurses in public psychiatric hospitals in Ghana.

\section{Methods}

\section{Study Design and Study Area}

This study employed a cross-sectional research design. It was conducted at the three public psychiatric hospitals in Ghana.

\section{Population and Sampling Procedure}

The population for this study included psychiatric nurses who work in the three public psychiatric hospitals in Ghana. A total of 993 nurses were recruited into the study. This comprises 462 nurses from Accra Psychiatric Hospital, 210 nurses from Ankaful Psychiatric Hospital and 321 nurses from the Pantang Hospital.

The sample size was determined by application of Miller and Brewer's formula [18]. It states that; at $95 \%$ confidence level; $n=\frac{N}{(1+N(a) 2)}$. Where, $n$ - desired sample size, $N$ - target population, a- level of statistical significance of $0.05,1$-is a constant.

Therefore, the sample size, $n=\frac{993}{(1+993(0.05) 2)}=285.139=285$ 
The calculated sample size of 285 was increased by $10 \%$ to 314 in order to ensure that samples are not lost during data collection and data cleaning and also to increase the statistical power [19]. The sample size for each hospital was determined from the calculated sample size of 314 proportionate to the populations from each hospital. In all, 146 nurses were recruited from the Accra Psychiatric hospital, 102 from the Pantang hospital and 66 from the Ankaful psychiatric hospital.

Simple random sampling procedure was used to obtain the required number of participants from each hospital. The questionnaires were administered by the first author and trained research assistants to all 314 respondents who were involved in this study at a convenient place in the various hospitals. Those who wanted to self-administer were given a period of one week to complete the questionnaire after which the researcher went around the various hospitals and collected them.

\section{Data Collection Instrument}

Data was collected using a questionnaire. The instrument consisted of five sections; the first section focused on socio-demographic characteristics of respondents. The second section centred on prevalence of work place risk factors for depression, anxiety and stress. The third section focused on prevalence of depression. Beck's Depression Inventory (BDI) was used to assess depression. The BDI is a 21-item selfreporting scale on a 4-point scale: 0- (Never- do not apply to me), 1- (Sometimes- applied to me to some degree), 2- (Often- applied to me to a considerable degree), 3- (Almost always- applied to me very much). It has a minimum score of 0 and a maximum score of 63 . The score of $0-13$ indicate (minimal depression), 14-19 (mild depression), 20-28 (moderate depression) and 29-63 (severe depression) [20].

In the fourth section, anxiety was assessed using Beck's Anxiety Inventory (BAI). It is a 21 -item self-report scale that is used to assess anxiety symptoms among adults on a 4-point Likert scale, which ranges from: 0- (Not at all), 1- (Mildly- but it didn't bother me much), 2- (Moderately-it wasn't pleasant at times), 3- (Severely- it bothered me a lot). A score of 0-21 indicate (low anxiety), 22-35 (moderate anxiety), score of 36 and above (potential concerning level of anxiety) [21].

The fifth section determined the prevalence of stress using the Perceived Stress Scale-10 (PSS). PSS is a 10 -item scale that is used to assess respondent's perception of stressful experiences over the previous month. Items on the scale are rated on a 5-point Likert scale which ranges from: 0- (Never), 1- (Almost Never), 2- (Sometimes), 3- (Fairly Often), 4- (Very Often). The scores were calculated after reversing the positive item's score. It has a minimum score of 0 and a maximum score of 40 , a high score indicates greater stress [22]. Six out of the 10 items of the PSS-10 are considered negative $(1,2,3,4,5,6)$ and the remaining 4 are positive $(7,8,9,10)$. A score of 0-13 represent (low stress), 14-26 (moderate stress) and 2740 (high perceived stress) [23].

Pre-testing of the instrument was conducted using 40 respondents at public hospitals with Mental Health Units in the Cape Coast Metropolis and Komenda-Edina-Eguafo-Abirem Municipality, Ghana to improve 
the validity and reliability of the instrument. The Cronbach's alpha reliability coefficients for the instrument was .910 after pre-testing.

\section{Data Analysis}

The responses were edited, coded and scored using Statistical Package for Social Sciences (SPSS) version 23.0 and descriptive statistics were used. The editing procedure was used to check whether respondents followed instructions correctly and to check if all items on the questionnaire were responded to. A 95\% confidence interval was considered for this study. Multinomial logistic regression was used to predict the socio-demographic characteristics influencing depression (minimal, mild, moderate, severe), anxiety (low, moderate, severe) and stress (low, moderate, high).

\section{Results}

\section{Demographic Data of Respondents}

Table 1 shows that, $60.1 \%$ of the respondents were females and $69.1 \%$ of them were between 25 to 34 age range. More than half $(59.5 \%)$ of the respondents were diploma holders. It was found that $46.6 \%$ of the nurses worked at Accra Psychiatric Hospital. The results revealed that, $28.3 \%$ of the respondents had spent 4 to 6 years in the nursing profession and $50.2 \%$ of them earned between 1500 to 2000 Ghana cedis monthly equivalent to $300-400$ US dollars. 
Table 1

Distribution of Demographic Variables of Respondents $\mathrm{N}=311$

\begin{tabular}{|c|c|c|}
\hline Variable & Frequency & Percentage (\%) \\
\hline \multicolumn{3}{|l|}{ Gender } \\
\hline Male & 124 & 39.9 \\
\hline Female & 187 & 60.1 \\
\hline \multicolumn{3}{|l|}{ Age } \\
\hline $18-24$ & 8 & 2.6 \\
\hline $25-34$ & 215 & 69.1 \\
\hline $35-44$ & 86 & 27.7 \\
\hline 45 and above & 2 & .6 \\
\hline \multicolumn{3}{|l|}{ Marital status } \\
\hline Single & 140 & 45.0 \\
\hline Married & 168 & 54.0 \\
\hline Divorced/separated & 2 & .6 \\
\hline Widowed & 1 & .3 \\
\hline \multicolumn{3}{|l|}{ Educational status } \\
\hline Diploma & 185 & 59.5 \\
\hline Bachelor's degree & 121 & 38.9 \\
\hline Master's degree & 5 & 1.6 \\
\hline \multicolumn{3}{|l|}{ Name of Hospital } \\
\hline Ankaful Psychiatric Hospital & 66 & 21.2 \\
\hline Accra Psychiatric Hospital & 145 & 46.6 \\
\hline Pantang Hospital & 100 & 32.2 \\
\hline \multicolumn{3}{|c|}{ Years spent in the nursing profession } \\
\hline Less than 1 year & 4 & 1.3 \\
\hline $1-3$ & 54 & 17.4 \\
\hline $4-6$ & 88 & 28.3 \\
\hline 7-9 & 84 & 27.0 \\
\hline
\end{tabular}




\begin{tabular}{|lll|}
\hline Variable & Frequency & Percentage (\%) \\
\hline 10 and above & 81 & 26.0 \\
\hline Department/ward & & \\
\hline Administration & 7 & 2.3 \\
\hline OPD & 49 & 15.8 \\
\hline Acute ward & 167 & 53.7 \\
\hline Chronic ward & 88 & 28.3 \\
\hline Monthly income & & \\
\hline Less than 1500 cedis & 40 & 12.9 \\
\hline 1500-2000 cedis & 156 & 50.2 \\
\hline 2100-2900 cedis & 106 & 34.1 \\
\hline 3000 cedis and above & 9 & 2.9 \\
\hline Religion & & \\
\hline Christianity & 282 & 90.7 \\
\hline Islam & 27 & 8.7 \\
\hline Traditional religion & 2 & .6 \\
\hline Source: Field Survey (2020) & & \\
\hline
\end{tabular}

Prevalence of depression, anxiety and stress among nurses in public psychiatric hospitals in Ghana.

The results in Table 2 shows that $92.0 \%$ of the study respondents experienced minimal depression whilst $2.3 \%$ experienced severe depression. It was found that $96.5 \%$ and $3.2 \%$ of the respondents experienced low and moderate anxiety respectively. It was observed that $56.6 \%$ of the respondents experienced low stress and $42.8 \%$ experienced moderate stress. 
Table 2

Distribution of Results of Prevalence of

Depression, Anxiety and Stress. $\mathrm{N}=311$

\begin{tabular}{|lll|}
\hline Variable & No. & $\%$ \\
\hline Depression & & \\
Minimal depression (0-13) & 286 & 92.0 \\
\hline Mild depression (14-19) & 16 & 5.1 \\
\hline Moderate depression (20-28) & 2 & .6 \\
\hline Severe depression (29-63) & 7 & 2.3 \\
\hline Anxiety & & \\
\hline Low anxiety (0-21) & 300 & 96.5 \\
\hline Moderate anxiety (22-35) & 10 & 3.2 \\
\hline Severe anxiety (36 and above) & 1 & .3 \\
\hline Stress & & \\
\hline Low stress (0-13) & 176 & 56.6 \\
\hline Moderate stress (14-26) & 133 & 42.8 \\
\hline High perceived stress (27-40) & 2 & .6 \\
\hline Source: Field Survey (2020) & & \\
\hline
\end{tabular}

Prevalence of work place risk factors of depression, anxiety and stress among nurses in public psychiatric hospital in Ghana.

Table 3 indicate that, $42.4 \%$ of the respondents indicated "No" to the statement "are you satisfied with your current job". The results showed that $35.7 \%$ indicated "Yes" to the statement "have you experience workplace violence in the past 1 month". Additionally, 92.3\% of the respondents indicated "No" to the statement "do you have a history of chronic illness" and 86.5\% responded "No" to the statement "Do you drink alcohol". 
Table 3

Distribution of Results of Risk Factors of Depression, Anxiety and Stress N=311

\begin{tabular}{|lllllll|}
\hline statement & Yes & \multicolumn{2}{c}{ No } & \multicolumn{3}{c|}{ Not sure } \\
\cline { 2 - 7 } & Freq & $\%$ & Freq & $\%$ & Freq & $\%$ \\
\hline Are you satisfied with your current job & 129 & 41.5 & 132 & 42.4 & 50 & 16.1 \\
\hline Do you work in a shift rotation pattern & 293 & 94.2 & 17 & 5.5 & 1 & 0.3 \\
$\begin{array}{l}\text { Have you experience workplace violence in the past 1 } \\
\text { month }\end{array}$ & 111 & 35.7 & 195 & 62.7 & 5 & 1.6 \\
\hline $\begin{array}{l}\text { Have you had conflict with colleagues at the work } \\
\text { place in the past 1 month }\end{array}$ & 46 & 14.8 & 255 & 82.0 & 10 & 3.2 \\
\hline $\begin{array}{l}\text { Do you have a history of chronic illness } \\
\text { Do you drink alcohol }\end{array}$ & 17 & 5.5 & 287 & 92.3 & 7 & 2.3 \\
\hline Source: Field Survey (2020) & 35 & 11.3 & 269 & 86.5 & 7 & 2.3 \\
\hline
\end{tabular}

\section{Socio-demographic characteristics that predict depression, anxiety and stress among nurses in public psychiatric hospitals in Ghana}

This study determined socio-demographic characteristics that predict depression, anxiety and stress among nurses in public psychiatric hospitals in Ghana. To achieve this, a multinomial logistic regression analysis was carried out between socio-demographic characteristics of respondents and the psychological distress dimensions (e.g., depression, anxiety and stress).

Table 4 presents how socio-demographic characteristics of respondents predict depression. The model comprised six predictors, namely, gender, age, department, education status, hospital and income. The criterion variable was depression levels of nurses working in psychiatric hospitals. The model fitting information for the above-specified model was found to be significant, $p=.008$. The goodness of fit indices revealed that the data fit the model, $p=.719$. The Nagelkekerke pseudo-R-square value was .540 indicating that the socio-demographic variables of the respondents accounted for $54 \%$ of the variances in depression levels of mental health nurses.

The education level of respondents was found to be significantly associated with depression. Precisely, diploma and bachelor degree holders were more likely than master's holders to be minimally depressed relative to severely depressed. It was found that the department of the respondents was associated with depression. Those working in the Administration and Out Patient Department (OPD) were less likely than those in Chronic Ward to be minimally depressed comparable to severely depressed. The income of nurses is positively and significantly associated with levels of depression. Nurses with income less than 1500 cedis equivalent to 300 United States dollars are more likely than those taking $3000+$ cedis 
Table 4

Socio-demographic Variables Prediction of Depression

\begin{tabular}{|c|c|c|c|c|c|c|}
\hline Depressio & & B & Std. Error & Wald & Sig. & $\operatorname{Exp}(B)$ \\
\hline minimal & Intercept & .405 & .913 & .197 & .657 & \\
\hline & Diploma & 3.643 & 1.083 & 11.322 & .001 & 38.222 \\
\hline & Bachelor's Degree & 3.611 & 1.159 & 9.713 & .002 & 37.000 \\
\hline & Administration & -3.490 & 1.309 & 7.115 & .008 & .030 \\
\hline & OPD & -2.032 & 1.134 & 3.212 & .007 & .131 \\
\hline & Acute Ward & 7.955 & 38.718 & .042 & .037 & 2849.968 \\
\hline & Less than 1500 cedis & 18.177 & 40.354 & .000 & .996 & 783.199 \\
\hline & $1500-2000$ cedis & 1.490 & 1.176 & 1.607 & .205 & 4.437 \\
\hline & $2100-2900$ cedis & 1.812 & 1.279 & 2.009 & .156 & 6.125 \\
\hline & Ankaful Psychiatric Hospital & -1.558 & 1.166 & 1.784 & .182 & .211 \\
\hline & Accra Psychiatric Hospital & -.777 & 1.163 & .447 & .504 & .460 \\
\hline & $18-24$ years & 15.084 & 666.813 & .982 & .001 & 355.253 \\
\hline & $25-34$ years & 3.674 & 1.485 & 6.121 & .013 & 39.400 \\
\hline & $35-44$ years & 4.382 & 1.736 & 6.374 & .012 & 80.000 \\
\hline & Male & -1.372 & .845 & 2.632 & .105 & .254 \\
\hline Mild & Intercept & -17.313 & .802 & 466.272 & .000 & .736 \\
\hline & Diploma & 18.412 & 1.043 & 311.776 & .000 & 991.935 \\
\hline & Bachelor's Degree & 18.566 & .000 & 231.667 & .000 & 1156.757 \\
\hline & Administration & -19.028 & 4284.067 & .000 & .096 & .449 \\
\hline & OPD & -2.303 & 1.396 & 2.719 & .099 & .100 \\
\hline & Acute Ward & 7.900 & 38.722 & .042 & .838 & 2696.508 \\
\hline & Less than 1500 cedis & 34.703 & 4061.354 & 7.021 & .009 & 117.000 \\
\hline & $1500-2000$ cedis & 18.484 & 1.021 & 313.954 & .000 & 714.344 \\
\hline & $2100-2900$ cedis & 18.090 & 67.000 & 3.713 & .000 & 107.516 \\
\hline
\end{tabular}

a. The reference category for criterion variable: severe.

Reference qroups for predictors: Education status- Masters; Department- Chronic Ward; Income-3,000 Loading [MathJax]/jax/output/CommonHTML/fonts/TeX/fontdata.js er-Female. 


\begin{tabular}{|llllll|}
\hline Ankaful Psychiatric Hospital & -1.386 & 1.384 & 1.003 & .317 & .250 \\
\hline Accra Psychiatric Hospital & -.288 & 1.302 & .049 & .825 & .750 \\
\hline 18-24 years & 16.911 & 3210.424 & 2.796 & .000 & 220.221 \\
\hline 25-34 years & 17.040 & 3109.286 & 1.906 & .000 & 251.227 \\
\hline 35-44 years & 17.183 & 3109.286 & 1.911 & .000 & 290.416 \\
\hline Male & -1.168 & .977 & 1.429 & .232 & .311 \\
\hline Intercept & -19.393 & 1.225 & 250.716 & .000 & 123.451 \\
\hline Diploma & 18.294 & 1.683 & 118.119 & .000 & 881.197 \\
\hline Bachelor's Degree & 18.699 & .000 & 114.181 & .000 & 132.296 \\
\hline Administration & -10.299 & .704 & 42.310 & .000 & .336 \\
\hline OPD & -2.002 & 167.881 & .207 & .009 & .135 \\
\hline Acute Ward & 17.204 & 106.706 & .026 & .008 & 296.237 \\
\hline Less than 1500 cedis & 18.218 & 18971.329 & .000 & .999 & 816.658 \\
\hline 1500-2000 cedis & 18.777 & 16902.236 & .000 & .999 & 142.193 \\
\hline 2100-2900 cedis & 1.891 & 17528.482 & .000 & .999 & 6.625 \\
\hline Ankaful Psychiatric Hospital & -1.528 & .000 & .987 & .873 & .217 \\
\hline Accra Psychiatric Hospital & 18.045 & .000 & .564 & .443 & 686.257 \\
\hline 18-24 years & 16.911 & 1414.522 & 2.990 & .000 & 220.267 \\
\hline 25-34 years & 5.625 & 236.233 & 1.981 & .001 & 277.188 \\
\hline 35-44 years & 18.857 & 23.080 & 9.023 & .000 & 154.868 \\
\hline Male & -.916 & 1.643 & .311 & .577 & .400 \\
\hline
\end{tabular}

a. The reference category for criterion variable: severe.

Reference groups for predictors: Education status- Masters; Department- Chronic Ward; Income-3,000 and above, Hospital- Pantang; Age- 45 and above, Gender-Female.

Table 5 presents the analysis of how socio-demographic variables of respondents predict anxiety. The model comprised six predictors, namely, gender, age, department, education status, hospital and income. The criterion variable was the anxiety levels of nurses working in psychiatric hospitals. The model fitting information for the above-specified model was found to be significant, $p=.026$. The goodness of fit indices revealed that the data fit the model, $p=.059$. The Nagelkekerke pseudo-R-square value was .380 
indicating that the socio-demographic variables of the respondents accounted for $38 \%$ of the variances in anxiety levels of mental health nurses.

The findings suggest that higher levels of education are associated with lower levels of anxiety. This is to say that nurses who have diploma degrees are more likely to be anxious than those with a master's degree. Nurses working at the Ankaful Psychiatric Hospital and Accra Psychiatric Hospital are likely to have higher levels of anxiety than those working in Pantang Hospital. This study indicate that the age of the respondents was associated with anxiety. Younger nurses are more likely to suffer from severe anxiety as compared to older nurses. Furthermore, the results also found that male nurses were more likely than female nurses to have low anxiety relative to severe anxiety. 
Table 5

Socio-demographic Variables Prediction of Anxiety

\begin{tabular}{|c|c|c|c|c|c|c|}
\hline Anxiety & & B & Std. Error & Wald & Sig. & $\operatorname{Exp}(B)$ \\
\hline low & Intercept & 20.335 & 1.803 & 127.237 & .000 & 67.906 \\
\hline & Diploma & -.137 & 1827.846 & 192.000 & .909 & .872 \\
\hline & Bachelor's Degree & -15.556 & 1.503 & 107.152 & .000 & .757 \\
\hline & Administration & 16.736 & 1.296 & 166.872 & .000 & 185.329 \\
\hline & OPD & 16.779 & 5856.834 & .001 & .998 & 193.958 \\
\hline & Acute Ward & 16.762 & 3170.651 & .003 & .996 & 190.986 \\
\hline & Less than 1500 cedis & -16.524 & 2322.514 & .006 & .994 & .663 \\
\hline & $1500-2000$ cedis & .041 & 3058.412 & .002 & .900 & 1.041 \\
\hline & $2100-2900$ cedis & .062 & 1.279 & .002 & .961 & 1.064 \\
\hline & Ankaful Psychiatric Hospital & -.014 & .852 & 1. 987 & .007 & .514 \\
\hline & Accra Psychiatric Hospital & -17.748 & .742 & 571.722 & .000 & .659 \\
\hline & 18-24 years & -7.736 & 128.941 & 34.952 & .004 & .390 \\
\hline & $25-34$ years & -7.692 & 24.253 & 76.751 & .010 & .683 \\
\hline & $35-44$ years & -14.969 & 1.735 & 74.396 & .000 & .155 \\
\hline & Male & 17.516 & .656 & 712.585 & .000 & 404.460 \\
\hline moderate & Intercept & 18.949 & 1.414 & 179.531 & .000 & 12.987 \\
\hline & Diploma & -1.848 & 182.846 & 111.000 & .045 & .158 \\
\hline & Bachelor's Degree & -18.949 & 127.000 & 219.000 & .007 & .896 \\
\hline & Administration & 18.693 & 59.000 & 318.087 & .076 & 131.333 \\
\hline & OPD & 16.658 & 5856.834 & .000 & .908 & 171.650 \\
\hline & Acute Ward & 17.222 & 3170.651 & .000 & .996 & 301.208 \\
\hline & Less than 1500 cedis & -18.082 & 2322.514 & .000 & .994 & .403 \\
\hline & $1500-2000$ cedis & -1.099 & 3058.412 & .000 & .980 & .333 \\
\hline & $2100-2900$ cedis & -1.810 & .000 & .000 & .342 & .164 \\
\hline
\end{tabular}

a. The reference category for the criterion variable is: severe anxiety

Reference aroups for predictors: Education status- Masters; Department- Chronic; Income-3,000 and Loading [MathJax]/jax/output/CommonHTML/fonts/TeX/fontdata.js emale. 


\begin{tabular}{|llllll|}
\hline Ankaful Psychiatric Hospital & -.507 & .000 & .000 & .326 & .602 \\
\hline Accra Psychiatric Hospital & -18.654 & .000 & .000 & .792 & .921 \\
\hline 18-24 years & -9.681 & 128.936 & 19.940 & .006 & .243 \\
\hline 25-34 years & -11.084 & 24.215 & 10.647 & .021 & .536 \\
\hline 35-44 years & -19.400 & 65.907 & 9.954 & .000 & .756 \\
\hline Male & 17.516 & 7.090 & 25.781 & .000 & 403.461 \\
\hline $\begin{array}{l}\text { a. The reference category for the criterion variable is: severe anxiety } \\
\text { Reference groups for predictors: Education status- Masters; Department- Chronic, Income-3,000 and } \\
\text { above, Hospital- Pantang; Age- 45 and above; Gender-Female. }\end{array}$ \\
\hline
\end{tabular}

Results from Table 6 presents how socio-demographic characteristics of respondents predict their level of stress. The model comprised six predictors, namely, gender, age, department, education status, hospital and income. The criterion variable was the stress levels of staff working in psychiatric hospitals. The model fitting information for the above-specified model was found to be significant, $p=.043$. The goodness of fit indices revealed that the data fit the model, $p=.107$. The Nagelkekerke pseudo-R-square value was .610 indicating that the socio-demographic variables of the respondents accounted for $61 \%$ of the variances in stress levels of mental health nurses.

There appears to be a negative association between educational level and stress such that nurses with higher educational level are more likely to experience lower levels of stress and vice versa. Additionally, it was found that, nurses in the Administration and OPD are more likely to be highly stressed than those in the Acute Ward and Chronic Ward. However, those in the Chronic Ward are more likely to have higher levels of stress than those in the Acute Ward. It can be indicated that the income of nurses is negatively and significantly associated with stress levels. Thus, nurses who take a higher amount of income are likely to experience low stress levels than those with relatively smaller income. The result generally indicates that, older nurses are likely to experience low levels of stress and younger nurses are more likely to have high levels of stress. 
Table 6

Socio-Demographic Variables Prediction of Stress

\begin{tabular}{|c|c|c|c|c|c|c|}
\hline Stress & & B & Std. Error & Wald & Sig. & $\operatorname{Exp}(B)$ \\
\hline low & Intercept & 16.931 & 1.506 & 126.357 & .000 & 24.12 \\
\hline & Diploma & -12.267 & 1.811 & 45.907 & .000 & .704 \\
\hline & Bachelor's Degree & -12.741 & 1.133 & 126.457 & .000 & .929 \\
\hline & Administration & -.251 & 6810.055 & 98.000 & .000 & .285 \\
\hline & OPD & -16.382 & 1101.237 & 64.000 & .008 & .683 \\
\hline & Acute Ward & .009 & .266 & 87.001 & .042 & 1.991 \\
\hline & Less than 1500 cedis & -.096 & 1531.205 & 1.000 & .000 & .909 \\
\hline & $1500-2000$ cedis & -13.668 & 775.087 & .986 & .000 & .156 \\
\hline & $2100-2900$ cedis & -.052 & .699 & .941 & .005 & .053 \\
\hline & Ankaful Psychiatric Hospital & -16.113 & 1124.354 & .989 & .000 & .106 \\
\hline & Accra Psychiatric Hospital & -.139 & .264 & .599 & .027 & .870 \\
\hline & $18-24$ years & -.219 & 1132.185 & 1.268 & .000 & .245 \\
\hline & $25-34$ years & -11.248 & 326.098 & .972 & .001 & .303 \\
\hline & $35-44$ years & -.080 & 1.431 & 9.955 & .003 & .083 \\
\hline & Male & -16.745 & .239 & 4920.261 & .000 & .342 \\
\hline moderate & Intercept & 15.544 & 1.009 & 237.230 & .000 & 7.983 \\
\hline & Diploma & -11.188 & 1.425 & 61.615 & .000 & .385 \\
\hline & Bachelor's Degree & -11.555 & 2.000 & 78.109 & .000 & .586 \\
\hline & Administration & -.391 & 810.550 & .000 & .900 & .676 \\
\hline & OPD & -16.407 & 101.732 & .000 & .908 & .488 \\
\hline & Acute Ward & .012 & 23.000 & .000 & .075 & 1.012 \\
\hline & Less than 1500 cedis & -.127 & 1531.205 & 1.0860 & .000 & .136 \\
\hline & $1500-2000$ cedis & -13.759 & 775.087 & .986 & .000 & .056 \\
\hline & $2100-2900$ cedis & -.068 & 665.000 & 1.765 & .000 & .934 \\
\hline
\end{tabular}

a. The reference category for the criterion variable is: high stress

Reference aroups for predictors: Education status- Masters; Department- Chronic, Income-3,000 and Loading [MathJax]/jax/output/CommonHTML/fonts/TeX/fontdata.js emale. 


\begin{tabular}{llllll}
\hline Ankaful Psychiatric Hospital & -16.045 & $3452 . .456$ & .989 & .000 & .076 \\
\hline Accra Psychiatric Hospital & .184 & .000 & .00 & .064 & 1.202 \\
\hline 18-24 years & -.292 & 1132.185 & 1.000 & .000 & .747 \\
\hline 25-34 years & -11.561 & 326.095 & .972 & .001 & .534 \\
\hline 35-44 years & -.107 & 98.090 & 2.456 & .000 & .899 \\
\hline Male & -17.221 & .604 & 238.054 & .000 & .318
\end{tabular}

a. The reference category for the criterion variable is: high stress

Reference groups for predictors: Education status- Masters; Department- Chronic, Income-3,000 and above, Hospital- Pantang; Age- 45 and above, Gender-Female.

\section{Discussion}

The aim of this study was to assess the prevalence and determinants of depression, anxiety and stress among psychiatric nurses in Ghana. This study revealed that an overwhelming majority of mental health nurses, over $90 \%$, experienced minimal depression and low anxiety. Stress, however, had a different trend of results in this study. Although, a larger percentage of mental health nurses experienced low stress (56.6\%), a relatively high number of them were moderately stressed $(42.8 \%)$. In our view, the presence of minimal depression and low anxiety does not necessarily mean that these two psychological distress variables are non-existent in the nursing career. Rather, it could be attributed to the fact that depression and anxiety among these mental health nurses in Ghana are being managed properly. Generally, it could be said that mental health nurses in this study experienced low to moderate stress.

Contrary to the findings of this study, [24-26] recorded moderate to a high prevalence of depression, anxiety and stress among nurses. However, in [26] study, more than half of the nurses experienced low to moderate stress levels which corroborates the findings of this study. These discrepancies observed between the findings of this study and previous studies could be attributed to differences in the study settings and population. Whereas this study focused on mental health nurses in Ghana, previous studies have concentrated on psychological distress among general nurses with only a few of them focusing on mental health nurses $[17,25]$.

Findings in this study revealed that the mental health nurses were not satisfied with their current job, probably, due to their conditions of work such as heavy workload, low salaries, low incentives, bad leadership, few equipment available for use, among others. Conditions at the workplace such as heavy workload, conflict and violence can be associated with a high risk of developing mental health condition among health care professionals $[6,13,27]$. Although their source of dissatisfaction is unknown, the understanding is that these sources of dissatisfaction pertain to the work. An obvious one, which was found in this study, is working in the shift rotation pattern, especially when the shift rotations come with Loading [MathJax]/jax/output/CommonHTML/fonts/TeX/fontdata.js $[$ ate with several other previous studies in this 
area. Studies conducted by $[1,13,17]$ have shown that the risk factors of depression, anxiety and stress among nurses include personal experience, economic status, emotional maturity, heavy workload, different shift rotation and work experience.

This study revealed that there is a positive association between educational level and depression such that nurses with higher educational level are more likely to have a higher level of depression and vice versa. However, the findings suggest that higher levels of education are associated with lower levels of anxiety. The study also found a negative association between educational level and stress. For instance, those with higher educational level are more likely to experience lower levels of stress and vice versa. This confirms the findings of [28] study in Taiwan, which found that nurses without degree showed high levels of job stress than nurses with a degree. [17] also found that nurses who obtained a university degree were more likely to develop depression and anxiety. However, [17] found a positive association, this study found a negative association.

Although the department where nurses work was not significantly associated with anxiety levels however, the association was significant in the case of depression and stress. The result found that mental health nurses working in Administration and OPD are more likely to have higher stress and depression levels than those in the Acute Ward and Chronic Ward. The findings of this study reflect the views of scholars that nurses who work in departments such as the emergency unit and intensive care units experience a high rate of mental health challenges as compared to other nursing staff because of increased workload and dealing with death situations $[1,13]$.

In this study, it can be indicated that the income of mental health nurses is positively and significantly associated with levels of depression. Thus, nurses who take a higher amount of income are more likely to have higher levels of depression than those who take a relatively smaller amount. It was found that the income of nurses is negatively and significantly associated with stress levels. This finding is consistent with the study by [9] who found that middle to high-income earners was less likely to suffer from stress. Whereas this study did not find any association between income and anxiety levels, [9] observed; there was a significant association between income and anxiety level.

Even though gender was not significantly associated with depression, the results suggest that female mental health nurses have higher chances of experiencing higher levels of anxiety. The findings further revealed that male mental health nurses have more chances of experiencing higher levels of stress. This is corroborated by [29] study, where male nurses had a significantly lower risk for anxiety when compared to female nurses.

\section{Conclusion}

Mental health nurses experienced minimal depression and low anxiety levels and a greater percentage of them experienced low to moderate stress levels. Heavy workload, conflict and violence at the work place were associated with a high risk of developing depression, anxiety and stress among nurses in public Loading [MathJax]/jax/output/CommonHTML/fonts/TeX/fontdata.js degree are more likely to experience depression 
than those with diploma however, mental health nurses with diploma are more likely to experience anxiety and stress than those with degree. These findings have implications on Continuing Professional Development programmes for mental health nurses on management of depression, anxiety and stress. Measures to facilitate the easy enrolment of mental health nurses into higher level of education should be instituted by stakeholders. It is suggested that, further research should examine the effects of depression, anxiety and stress on mental health nurses' work performance.

\section{List Of Abbreviations}

BAI Beck's Anxiety Inventory

BDI Beck's Depression Inventory

OPD Out Patients Department

PSS Perceived Stress Scale

SPSS Statistical Package for Social Sciences

WHO World Health Organization

\section{Declarations}

\section{Ethics approval and consent to participate}

This study was performed in accordance with the Declaration of Helsinki and approved by the Institutional Review Board of the University of Cape Coast with reference ID (UCCIRB/CHAS/2019/210). The purpose of the study, anonymity, voluntary participation and confidentiality of the information was explained to the respondents to seek their informed consent. Written consent was obtained from each of the study respondents before data collection. Participation in this study was voluntary and respondents could pull out from it at any point in time without any adverse effect.

\section{Consent for publication}

Not applicable

\section{Availability of data and materials}

The datasets used and/or analysed during the current study are available from the corresponding author on reasonable request.

\section{Competing interests}

The authors declare that, they have no competing interests. 


\section{Funding}

The study was funded by the Samuel and Emelia Brew-Butler- SGS/GRASAG Research Grant, University of Cape Coast, Ghana.

\section{Authors' contributions}

All authors contributed to the conception and design of the study; SOA and NIEE contributed to the collection of data; SOA, JPN and NIEE contributed to data analysis and interpretation; All authors read and approved the final manuscript submitted.

\section{Acknowledgements}

We will like to thank the staff and management of Ankaful, Accra and Pantang Psychiatric hospitals for their contribution given to the research and the Samuel and Emelia Brew-Butler-SGS/GRASAG Research Grant, University of Cape Coast, Ghana, that funded it.

\section{References}

1. Khodadadi E, Hosseinzadeh M, Azimzadeh R, Fooladi M. The relation of depression , anxiety and stress with personal characteristics of nurses in hospitals of Tabriz , Iran. Int J Med Res Heal Sci. 2016;5(5):140-8.

2. Ferrari AJ, Somerville AJ, Baxter AJ, Norman R, Patten SB, Vos T, et al. Global variation in the prevalence and incidence of major depressive disorder: A systematic review of the epidemiological literature. Psychol Med. 2013;43(3):471-81.

3. World Health Organization. Depression and other common mental disorders: Global health estimates. Geneva World Heal Organ. 2017;1(24).

4. Marcus M, Taghi YM, van Ommeren M, Chisholm D, Saxena S. Depression: A global public health concern. World Ment Heal Day. 2012;

5. Murray CJL, Vos T, Lozano R, Naghavi M, Flaxman AD, Michaud C, et al. Disability-adjusted life years (DALYs) for 291 diseases and injuries in 21 regions, 1990-2010: A systematic analysis for the global burden of disease study 2010. Lancet. 2012;380(9859):2197-223.

6. Ghazwin MY, Kavian M, Ahmadloo M, Jarchi A, Javadi SG, Latifi S, et al. The association between life satisfaction and the extent of depression, anxiety and stress among Iranian nurses: A multicenter survey. Iran J Psychiatry. 2016;11(2):120-7.

7. Clark D, Beck AT. Anxiety: A common but multifaceted condition. Cogn Ther Anxiety Disord Sci Pract [Internet]. 2010;3-30. Available from: https://www.guilford.com/excerpts/clark5.pdf

8. Usman A, Akbar Z, Ahmed Z, Ahmed I. Work stress experienced by the teaching staff of university of the Punjab, Pakistan: Antecedents and consequences. Int J Bus Soc Sci. 2011;2(8):202-10. 
9. Yeshaw Y, Mossie A. Depression, anxiety, stress, and their associated factors among Jimma university staff, Jimma, southwest Ethiopia, 2016: A cross-sectional study. Neuropsychiatr Dis Treat. 2017;13:2803-12.

10. Clark DA, Beck AT. Cognitive theory and therapy of anxiety and depression: Convergence with neurobiological findings. Trends Cogn Sci [Internet]. 2010;14(9):418-24. Available from: http://dx.doi.org/10.1016/j.tics.2010.06.007

11. Fradelos E, Tzitzikos G, Giannouli V, Argyrou P, Vassilopoulou C, Theofilou P. Assessment of burn-out and quality of life in nursing professionals: the contribution of perceived social support. Heal Psychol Res. 2014;2(1):11-2.

12. Id CLH, Wu M, Ho C, Wang J. Risks of treated anxiety, depression, and insomnia among nurses: A nationwide longitudinal cohort study. PLoS One. 2018;13(9):10-4.

13. Koinis A, Giannou V, Drantaki V, Angelaina S, Stratou E, Saridi M. The impact of healthcare workers job environment on their mental-emotional health. Coping strategies: the case of a local general hospital. Heal Psychol Res. 2015;3(1).

14. Perry L, Lamont S, Brunero S, Gallagher R, Duffield C. The mental health of nurses in acute teaching hospital settings: A cross-sectional survey. BMC Nurs [Internet]. 2015;14(1):1-8. Available from: ???

15. Papathanasiou I V. Work-related mental consequences: Implications of burnout on mental health status among health care providers. Acta Inform Medica. 2015;23(1):22-8.

16. Elhai, J. D., Hall, B. J., \& Erwin MC. Emotion regulation's relationships with depression, anxiety and stress due to imagined smartphone and social media loss. Psychiatry Res [Internet]. 2018;261(2834). Available from: https://doi.org/10.1016/j.psychres.2017.12.045

17. Tsaras K, Aristides D, Mitsi D, Papathanasiou I V., Tzavella F, Zyga S, et al. A cross-sectional study for the impact of coping strategies on mental health disorders among psychiatric nurses. Heal Psychol Res. 2018;6(1):9-15.

18. Miller, R. L. \& Brewer JD. The A-Z of social research- A dictionary of key social science research concepts. London: Sage; 2003.

19. Bryman A. Why do researchers integrate/combine/mesh/blend/mix/merge/fuse quantitative and qualitative research. Adv Mix methods Res. 2008;87-100.

20. Jackson-Koku G. Beck depression inventory. Occup Med (Chic III). 2016;66(2):174-5.

21. Oh H, Park K, Yoon S, Kim Y, Lee S-H, Choi YY, et al. Clinical utility of Beck anxiety inventory in clinical and nonclinical Korean samples. Front Psychiatry. 2018;9(December):1-10.

22. Andreou E, Alexopoulos EC, Lionis C, Varvogli L, Gnardellis C, Chrousos GP, et al. Perceived Stress Scale: Reliability and validity study in Greece. Int J Environ Res Public Health. 2011;8(8):3287-98.

23. Herrero, J. \& Meneses J. Short web-based versions of the perceived stress (PSS) and center for epidemiological studies-depression (CESD) Scales: A comparison to pencil and paper responses among internet users. Comput Hum Behav. 2006;22(5):830-46. 
24. Tsaras, Konstantinos PI, Vus V, Katsou MA, Kelesi M, Evangelos C. Predicting Factors of Depression and Anxiety in Mental Health Nurses: A Quantitative Cross-Sectional Study. 2018;72(1):62-7.

25. Jordan TR, Khubchandani J, Wiblishauser M. The impact of perceived stress and coping adequacy on the health of nurses: A pilot investigation. Nurs Res Pract. 2016;2016:1-11.

26. Maharaj S, Lees T, Lal S. Prevalence and risk factors of depression, anxiety, and stress in a cohort of Australian nurses. Int J Environ Res Public Health. 2019;16(1).

27. Tran TTT, Nguyen NB, Luong MA, Bui THA, Phan TD, Tran VO, et al. Stress, anxiety and depression in clinical nurses in Vietnam: A cross-sectional survey and cluster analysis. Int $\mathrm{J}$ Ment Health Syst [Internet]. 2019;13(1):1-11. Available from: https://doi.org/10.1186/s13033-018-0257-4

28. Chen $\mathrm{CH}$, Wang J, Yang CS, Fan JY. Nurse practitioner job content and stress effects on anxiety and depressive symptoms, and self-perceived health status. J Nurs Manag. 2016;24(5):695-704.

29. Huang CLC, Wu MP, Ho CH, Wang JJ, Id CLH, Wu MP, et al. Risks of treated anxiety, depression, and insomnia among nurses: A nationwide longitudinal cohort study. PLoS One. 2018;13(9):10-4. 